\title{
OS MISERÁVEIS DA LEI: UMA ANÁLISE DA DESIGUALDADE SOCIAL NO SISTEMA PUNITIVO BRASILEIRO A PARTIR DO ROMANCE OS MISERÁVEIS DE VICTOR HUGO
}

\author{
THIAGO BARBOSA LACERDA ${ }^{1}$ \\ Arquimedes Fernandes Monteiro de Melo ${ }^{2}$
}

\begin{abstract}
RESUMO: Os miseráveis é uma obra grandiosa não pelo longo texto, mas principalmente por conseguir tratar de forma tão simples o complexo debate acerca do ideal de justiça. Através da saga de Jean Valjean, condenado à prisão por roubar um pão, Victor Hugo desnuda toda a crueldade da sociedade francesa do século XIX, denunciando sua extrema desigualdade social e seu sistema judiciário tendencioso. $\mathrm{O}$ autor alerta que a obra seria necessária enquanto situações semelhantes às narradas no livro perdurassem. Quase duzentos anos depois, no Brasil do século XXI, há semelhança surpreendente com a realidade francesa: mulheres e homens miseráveis, levados à criminalidade pela extrema pobreza e recebendo a punição desproporcional de um sistema judiciário seletivo. Assim, o objetivo do artigo é traçar os paralelos entre o tempo e espaço de Os miseráveis e a realidade brasileira, por meio de uma análise da prática punitiva vigente. Utilizando-se da revisão de bibliografia, tanto do Direito quanto de áreas correlatas, além de estudos estatísticos do Brasil contemporâneo, busca-se traçar paralelos entre as duas realidades. Esse estudo demonstra de forma assustadora a atualidade da obra de Victor Hugo, quando analisada à luz dos dados coletados, demonstrando a premente necessidade de explorá-la.
\end{abstract}

Palavras-Chave: sistema penal; desigualdade social; punitivismo da miséria.

1 Graduando em Direito pelo Centro Universitário Tabosa de Almeida (ASCES/UNITA). Graduado em Ciências Biológicas pela Universidade de Pernambuco (UPE), Caruaru (PE), Brasil. CV Lattes: http://lattes.cnpq.br/5241881791713504. ORCID: https://orcid.org/o000-0003-2409-0568. E-mail: thiagolacerdah@yahoo.com.br.

2 Doutor em Produtos Naturais e Sintéticos Bioativos pela Universidade Federal da Paraíba (UFPB). Mestre em Ciências Farmacêuticas pela Universidade Federal de Pernambuco (UFPE). Graduado em Farmácia pela Universidade Federal de Pernambuco (UFPE). Docente pelo Centro Universitário Tabosa de Almeida (ASCES/UNITA). Caruaru (PE), Brasil. $\quad C V \quad$ Lattes: http://lattes.cnpq.br/9070169199863154. ORCID: https://orcid.org/o000-0002-8702-6136. E-mail: arquimedesmelo@asces.edu.br. 


\section{INTRODUÇÃO}

O campo de estudo do Direito e Literatura tem crescido ao longo dos últimos anos. Embora essa aproximação, num primeiro momento, possa provocar estranheza, uma análise mais apurada encontrará mais semelhanças que disparidades.

É trabalho da crítica literária debruçar-se sobre um texto, explorando seus significados, buscando desvendar as intenções do autor, expressas nas construções linguísticas, na narrativa e em todo um contexto histórico e cultural. Da mesma forma ocorre com o estudioso dos fenômenos jurídicos, que tem como matéria-prima o texto da lei, e a partir dele explora uma gama de interpretações, tendo como uma das principais tarefas descobrir o melhor sentido possível, que passa pela análise dos textos e inclui também a investigação sobre as vontades do legislador. Godoy (2003, p. 134) sintetiza bem essa relação ao verificar que "a interpretação cria o texto, do mesmo modo que dá gênese e vida ao Direito. Leituras possibilitam procedimentos hermenêuticos que revelam reservas de sentido, descortinando a vida real de enredos, tramas, urdiduras”. Schwartz (2006, p. 1015) define o ponto de contato no sentido de que "Direito e Arte são abstrações construídas sobre outras abstrações (normas e obras). Assim, no plano das estratégias cognitivas, inexiste diferença entre abstrações de abstrações. O processo de conhecimento, portanto, da Arte e do Direito são correlatos”. Llanos (2017, p. 350), por sua vez, fala do caráter ficcional da norma jurídica, que elabora abstrações:

o Direito cria ficções sociais que são juridicamente reais
(cidadãos, estrangeiros, sociedade, nação,
responsabilidade objetiva etc.), considerando o fato de
que esse Direito está constitutivamente pleno de
histórias, escritas por legisladores, juízes e letrados, sobre
o bem e o mal, sobre os motivos para ter razão, sobre o
poder e a vulnerabilidade, a família, a educação e a saúde,
a vida e a morte, o indulto e o perdão, etc.

Olivo (2013, p. 20) sustenta ser essa relação mais do que uma abordagem interessante, afirmando que "é possível melhor compreender a questão da interpretação do Direito através do método comparativo com outros campos do conhecimento, e em especial a Literatura”. Tanto Olivo (2013) como Godoy (2003) fazem referência ao trabalho de Dworkin, que estava, segundo Dmitruk (2007, p. 144), "preocupado com a definição positivista do Direito, que o reduz a um modelo de regras e que autoriza o 
juiz a utilizar o poder discricionário ao se deparar com casos complexos”. É essa limitação dogmática que Moreira (2014, p. 30) assim define:

O positivismo jurídico era adjetivado por ser um "sistema fechado". Isso quer dizer que o juiz deveria se ater à lei, ao que estava escrito no ordenamento, sem se envolver e interpretar a norma. [...] Existindo essa rigidez, é óbvio afirmar então que no positivismo, o direito não se relacionava com mais nenhuma ciência. Apenas a lei bastava e tudo deveria ser decidido com base na sua forma e não na sua substância.

Aliás, é justamente no campo do positivismo, com sua rigidez na aplicação da norma, que a literatura tem mais a contribuir com o Direito. É por meio dessa expressão artística que se tem a liberdade de questionar, refletir e apontar soluções para o sistema jurídico de forma livre, sem os entraves dos árduos processos legislativos e do inacessível aparato judicial. A vantagem da literatura reside no seu poder de transformação do pensamento, não apenas como mero panfleto, mas com uma potencialidade de envolvimento muito maior por parte do leitor. Isso se dá por meio de exercícios de empatia, já que temas extremamente relevantes são tratados em um contexto pessoal, dentro de uma trama que envolve emocionalmente o receptor, colocando-o no lugar de outro, como se o outro fosse.

Mais do que mero entretenimento, a literatura pode contribuir para verdadeiras revoluções sociais e culturais, dada sua capacidade atrativa. Foi o que constatou Hunt (2007, p. 38) em seu estudo sobre o desenvolvimento dos Direitos Humanos:

Romances como Júlia levavam os leitores a se identificar com personagens comuns, que lhes eram por definição pessoalmente desconhecidos. Os leitores sentiam empatia pelos personagens, especialmente pela heroína ou pelo herói, graças aos mecanismos da própria forma narrativa. Por meio da troca fictícia de cartas, em outras palavras, os romances epistolares ensinavam a seus leitores nada menos que uma nova psicologia e nesse processo estabeleciam os fundamentos para uma nova ordem política e social. Os romances apresentavam a ideia de que todas as pessoas são fundamentalmente semelhantes por causa de seus sentimentos íntimos, e muitos romances mostravam em particular o desejo de autonomia. Dessa forma, a leitura dos romances criava um senso de igualdade e empatia por meio do envolvimento apaixonado com a narrativa. Seria coincidência que os três maiores romances de identificação psicológica do século XVIII - Pamela (1740) e Clarissa (1747-8), de Richardson, e Júlia (1761), de Rousseau - tenham sido todos publicados no período 
que imediatamente precedeu o surgimento do conceito dos "direitos do homem"?

E é nas revoluções do século XIX que Victor Hugo lança as bases de sua obra-prima, Os miseráveis. Colocando a escória da sociedade francesa como protagonista, o autor seduz o leitor para viver na pele o cotidiano das sarjetas de Paris, abrindo as cloacas da cidade-luz e questionando um mundo que entrega as esperanças ao governo das leis. Esse romance faz parte de uma trilogia, como assim definiu o próprio autor na introdução de Os trabalhadores do mar (Hugo, 1979, p. 11):

A religião, a sociedade, a natureza: tais são as três lutas
do homem. Estas três lutas são ao mesmo tempo as suas
três necessidades; precisa crer, daí o tempo; precisa criar,
daí a cidade; precisa viver, daí a charrua e o navio. Mas
há três guerras nestas três soluções. Sai de todas a
misteriosa dificuldade da vida. O homem tem de lutar
com o obstáculo sob a forma de superstição, sob a forma
preconceito e sob a forma elemento. Tríplice ananke pesa
sobre nós, o ananke dos dogmas, o ananke das leis, o
ananke das coisas. Na Notre-Dame de Paris o autor
denunciou o primeiro; nos Miseráveis, mostrou o
segundo; neste livro indica o terceiro.

Assim, será o anacronismo da lei o tema principal de Os miseráveis, como algo que é ao mesmo tempo necessário - dada a inevitabilidade do convívio em sociedade -, mas capaz de provocar conflitos e perpetuar injustiças. O ananke é usado aqui como fatalidade, algo de que não se pode escapar, sendo encarnado no romance na figura do inspetor Javert - a personificação da lei e do estado - em sua caçada implacável ao miserável Jean Valjean. Esse ananke pode ser traduzido nas palavras de Lyra Filho (2012, p. 8, apud Santos, 2017), ao dizer que a "legislação abrange, sempre, em maior ou menor grau, Direito e Antidireito: isto é, Direito propriamente dito, reto e correto, e negação do Direito, entortado pelos interesses classísticos e caprichos continuístas do poder estabelecido”. Uma definição que pode soar natural no mundo contemporâneo, mas destoante no contexto de Hugo.

O século XIX nascia sob os auspícios de um novo soberano. As grandes revoluções - americana e francesa - estabeleciam o início do constitucionalismo, espalhando pelo mundo um modelo de governo em que a soberania estava com a lei. Todos deveriam curvar-se a ela. A obediência aos princípios legais seria a solução contra a tirania, encantando um mundo 
já saturado de tanto despotismo, "pois não devem governar os homens; devem governar as leis!" (Dimoulis, 2011, p. 86).

Nesse mundo que consolidava seus códigos orgulhosamente e em uma França que se considerava o berço dessa nova razão, Victor Hugo vai dizer que "o dogma pode conter erros, o código não é completo, a sociedade não é perfeita, a autoridade pode vacilar, um desacordo no imutável é possível, os juízes são homens, a lei pode enganar-se, os tribunais podem errar" (Hugo, 2012, p. 1787) e que "por efeito de leis e costumes" (Hugo, 2012, p. 27) haveria miséria no mundo. Era, de fato, uma opinião que destoava do otimismo intelectual da época, mas que era um prognóstico do que viria pela frente nesse mundo dito civilizado, como constatou Vieira (1994, p. 72), ao reconhecer que “os totalitarismos do século XX demonstraram a fragilidade do direito estatal em assegurar os direitos essenciais da pessoa humana".

A opinião de Hugo estava baseada em intensa pesquisa. Seus livros eram resultado do que encontrava no mundo real, e não o contrário. Ferreira (2016, n.p.) assim definiu a gênese da produção literária do francês:

Foi no ano de 1824, contando apenas 22 anos de vida, que o autor [...] embrenhou-se nas mazelas e na escuridão do mundo da penalização, da fobia e do terrível enclausuramento. Nesse ambiente suas pesquisas trouxeram a vida não mais que um personagem excelente, mas também as sequelas que o próprio autor imaginava que tal sujeito lá preso teria após sua liberdade. Hugo assim criou Jean Valjean: de dentro de um dos mais atrozes presídios da França.

A realidade onipresente nessas pesquisas e, consequentemente, na ficção do autor era a questão penal. O escritor peruano Mario Vargas Llosa (2012, p. 11) diz que esse interesse remonta à infância de Victor Hugo:

Ao voltar à França em 1812, ele viu pela primeira vez um patíbulo e a imagem do homem que ia ser submetido ao "garrote", "montado de costas sobre um asno, rodeado de padres e penitentes", ficou gravada, como que a ferro e fogo, em sua memória. Pouco depois, ele viu numa cruz os restos de um homem esquartejado, e isso o impulsionaria, anos mais tarde, a falar com horror a respeito da ferocidade do ocupante francês contra os resistentes. É possível que dessas atrozes experiências da infância tenha nascido a sua rejeição contra a pena de morte - contra a qual lutou sem descanso -, a única convicção política à qual foi fiel ao longo de sua vida. 
Esse engajamento político contra a pena de morte e também contra as práticas desumanas nos presídios é que faz de Os miseráveis um objeto de estudo também no Direito Penal e não apenas no campo da crítica literária. Victor Hugo visitou diversas prisões francesas, em especial as temíveis galés $^{3}$, relatou em detalhes vívidos todo o destino dos condenados, desde o transporte até a vida como ex-prisioneiro; analisou criticamente todo o sistema legal de punição francês, da produção das leis aos julgamentos tendenciosos nas cortes penais. Segundo Broca (2010), foi, "visitando o presídio de Toulon, que o escritor tomara várias notas, principalmente sobre o forçado Pierre Maurin, do qual faria o tipo de Jean Valjean” e também na Conciergerie 4 "percorreu todos os recantos da prisão inclusive as celas reservadas para os menores, sobre os quais nos dá impressões interessantíssimas" (Broca, 2010). Pierre Maurin, assim como o futuro personagem de Hugo, foi condenado pelo roubo de um pão. E esse é o ponto de partida da crítica feita no romance.

\section{A MISÉRIA COMO PROTAGONISTA NO DIREITO PENAL}

Todo o questionamento em torno do autoritarismo da lei e a questão penal na obra de Victor Hugo parte da desigualdade social. Para o autor, o sistema judiciário, a despeito de evocar imparcialidade, reproduz a mesma discrepância de tratamento encontrada em qualquer lugar, variando a elaboração e aplicação da norma à medida que o indivíduo avança na pirâmide da sociedade. Para deixar evidente essa constatação, o escritor irá escolher três ícones da miséria parisiense para ilustrar a realidade: o presidiário, a prostituta e o menino de rua.

Para Broca (2010, n.p.), "seu propósito seria fazer dela uma suma de todos os problemas que lhe preocuparam o espírito de justiça social. Queria encerrar no livro toda uma mensagem à humanidade”. Mais uma vez constata-se um pioneirismo por parte do autor, já que a pobreza, embora severamente sentida na Europa de então, continuava ignorada tanto no

3 Embarcação muito esguia, com cerca de 20 a 50 metros por cinco de largura, dotada de dois castelos, um à popa outro à proa, a galé era movida a remos, em geral uns 30 a 60 (metade em cada bordo), remos esses que oscilavam entre os 9 e os 12 metros de comprimento. Cada remo era entregue a três ou quatro forçados, o que dá qualquer coisa como 90 a 240 homens em cada embarcação (Braga, 1999, p. 187).

4 Antigo palácio francês que se tornou uma das principais prisões francesas a partir do século XV. 
mundo das leis como no da arte. Ribeiro (2012, p. 20) confirma o sucesso do francês em atingir seus objetivos: "Victor Hugo foi o maior responsável por se constituir, na França e num mundo inteiro que lia e sentia com base na cultura francesa, uma preocupação com a miséria”, acrescentando ainda que a sociedade era o destinatário principal da acusação, pois "todas as peripécias do romance resultam dos erros que nos envolvem por todos os lados, e até a polícia, com seus instrumentos de repressão, é envolvida pelo erro" (Ribeiro, 2012, p. 26). A intenção de universalidade da obra foi alcançada e houve até uma versão brasileira do romance, intitulada "Os verdadeiros miseráveis" (Broca, 2010), de Manuel Antonio Major.

E é o Brasil um dos países onde a lógica que inspirou Os miseráveis permanece inalterada. A lógica cruel não da falta de recursos, mas de uma distribuição extremamente desigual. Na França do século XIX coexistiam duas sociedades, uma que inspirava e servia de modelo para todo o mundo ocidental, com sua cultura vanguardista e sofisticada, e outra, na qual "Dante julgaria ver ali os sete círculos do inferno em marcha" (Hugo, 2012, p. 1250). Contraste facilmente verificado no Brasil, que se enquadra em um grupo de países em que subsiste a pobreza absoluta, “aqueles nos quais o produto nacional é suficientemente elevado para garantir o mínimo necessário a todos, de modo que a pobreza resulta da má distribuição de renda" (Rocha, 2000, p. 3).

Essa desigualdade está intimamente relacionada aos índices de violência; "Na literatura internacional, inúmeros autores têm apontado a relação existente entre desigualdade socioeconômica e criminalidade" (Cerqueira et al., 2005, p. 9). Fajnzylber e Araujo Jr. (2001, p. 8) afirmam que "a desigualdade na distribuição de renda deveria estar associada a maiores taxas de crime”. De acordo com Resende e Andrade (2011, p. 174), "apesar dos resultados nem sempre serem convergentes, muitos trabalhos encontram coeficientes positivos e significativos para a desigualdade de renda como determinante da violência urbana”. O assunto tem sido debatido largamente nos campos da sociologia, criminologia, psicologia e até mesmo da economia. Trabalhos como os de Hagan e Petersen (1995) e Fajnzylber, Lederman e Loayza (1998) tentam vincular razões como a sensação de frustração por parte da população menos favorecida materialmente ou os efeitos da pobreza sobre o comportamento moral. 
As pesquisas no Brasil sobre essa relação, segundo Resende e Andrade (2011), baseiam-se em geral nas taxas de homicídio, considerando tanto as vítimas desse tipo de infração como os infratores. Carvalho, Cerqueira e Leão (2005) fizeram estudo em que calcularam a probabilidade de alguém ser vítima de homicídio, considerando diversas variáveis socioeconômicas, como renda per capita, índice de desigualdade de renda, intensidade de pobreza, crianças fora da escola etc. Concluíram que "os resultados empíricos sugeriram [...] o efeito das condições socioeconômicas para alimentar a dinâmica dos homicídios" (Cerqueira et al., 2005, p. 12).

Segundo Mendonça, Sachsida e Loureiro (2003, p. 2), no entanto, “a pobreza, por si mesma, não surge como fator que desencadeia a criminalidade”. Como enfatizam Fernandes e Fernandes (2012, p. 333), “para a eclosão do delito, também contribuem outras camadas do estamento social, situadas na esfera dos socialmente mais desenvolvidos", como é o caso dos chamados crimes de colarinho branco. De fato, segundo os criminologistas, não há que se falar em um só ou poucos fatores na origem da criminalidade, mas da combinação complexa de elementos. A escola de Chicago, por exemplo, cita elementos como o surgimento de grandes centros urbanos como fator desestabilizante e desencadeador de condutas criminosas:

No entendimento desses autores, a mobilidade social, assim como a divisão do trabalho, destruíram as formas clássicas de controle social, tal como estabelecia a família, a vizinhança, os grupos comunitários locais. A ruptura dos vínculos locais e a debilitação das restrições e inibições do grupo primário, sob a influência do ambiente urbano, é em grande medida a responsável pelo aumento das condutas delituosas nas cidades grandes (Shecaira, 2014, p. 147).

O nível de educação, por exemplo, é visto por muitos como um antídoto para o crime. Fernandes e Fernandes (2012), entretanto, argumentam que a criminalidade decorrente da má educação está mais relacionada à educação no sentido de exemplo do que meramente em anos formais de estudo. Assim, as pequenas corrupções do cotidiano, no caso do Brasil, seriam um exemplo de má educação que não estaria necessariamente vinculada ao estudo formal. Haveria, na sociedade brasileira, certa ideia de impunidade tolerável, ou, em outros termos, "um jeitinho", que funcionaria como um fator de influência à conduta delituosa. Há ainda uma série de outros elementos, como profissão, migração, política etc., segundo Garrido (2016), que podem contribuir para a criminalidade. 
Portanto, é preciso considerar se são os pobres que mais cometem crimes, ou se os crimes analisados nas pesquisas (que verificam a probabilidade do fator socioeconômico) são aqueles mais comuns entre os pobres. Em estudo sobre a população carcerária brasileira, Monteiro e Cardoso (2013, p. 102) constataram que

\begin{abstract}
A maioria das pessoas que estão no sistema prisional cometeu delitos enquadrados no grande grupo "crimes contra o patrimônio" (51,9\%). Além disso, de todos esses crimes, $83,5 \%$ foram de roubo e furto e apenas $6,1 \%$ latrocínio (roubo seguido de morte). Crimes graves, como os de homicídios ou mesmo de tráfico internacional de drogas apresentaram percentuais baixos em relação aos outros crimes ligados à propriedade. Em relação a crimes que estão vinculados à qualificação e maior tempo desprendido no planejamento e execução, como os crimes contra a fé pública ou contra a administração pública, os percentuais não chegam a $1 \%$.
\end{abstract}

O estudo conclui ainda que as prisões brasileiras, cuja população é em sua maioria pobre, "não estão repletas de criminosos perigosos e violentos, mas de condenados por negócios com drogas, furto, roubo ou atentado à ordem pública” (Monteiro; Cardoso, 2013, p. 104). Dados do último relatório do Infopen (Levantamento Nacional de Informações Penitenciárias), de dezembro de 2014 (Gráfico 1), confirmam que crimes como roubo e tráfico "respondem, sozinhos, por mais de 50\% das sentenças das pessoas condenadas atualmente na prisão. É importante apontar o grande número de pessoas presas por crimes não violentos” (Moura; Ribeiro, 2015, p. 33).

Conclusão parecida é a que chegaram Resende e Andrade (2011, p. 190), em sua pesquisa sobre a criminalidade nas grandes cidades: "os resultados indicam que a desigualdade de renda é um fator determinante de crimes orientados para a transferência de propriedade, mas não tanto para crimes passionais contra a vida ou contra a pessoa”. Barros Filho (2014, p. 50) diz que "o sistema penitenciário está repleto de pessoas de grupos socialmente excluídos: pobres, negros, com baixa escolaridade, discriminados e marginalizados". Vendo por essa perspectiva, fica claro que se pune com mais frequência os crimes típicos da parcela mais desfavorecida da população, mesmo quando estes têm um potencial ofensivo insignificante, comparado com outras modalidades. 


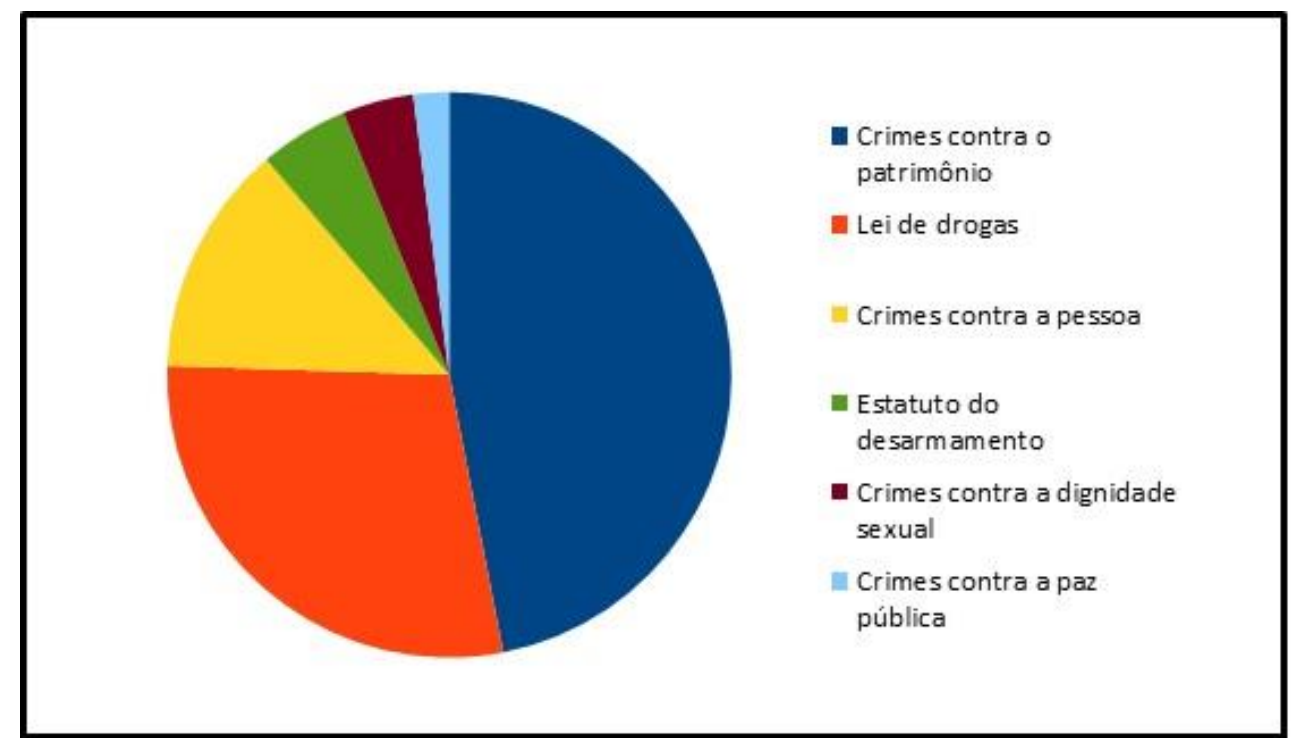

Gráfico 1 - Distribuição das sentenças de pessoas presas no Brasil por grandes categorias5

Até mesmo a aplicação de penas alternativas é determinada, na prática, pelo perfil social. Pellegrini (2011) alerta que "a atuação da polícia e as decisões de juízes sobre quais infratores podem ou não usufruir do direito a penas alternativas ainda se baseiam em perfis raciais e socioeconômicos discriminatórios, oriundos do século XIX”.

Essa afirmação fica mais evidente quando comparada com os crimes típicos das classes média e alta. Adorno (2002, p. 50) verifica que são “altas as taxas de impunidade para crimes do colarinho branco cometidos por cidadãos procedentes das classes médias e altas da sociedade”. Coleman (2005, p. 2), por sua vez, demonstra que são esses crimes que têm efeitos mais devastadores para a sociedade e, portanto, deveriam ter uma atenção maior parte do judiciário:

Estima-se que as perdas provocadas por violações das leis antitruste - apenas um item de uma longa lista dos principais crimes do colarinho branco - sejam maiores do que todas as perdas causadas pelos crimes notificados à polícia em mais de uma década, e as relativas a danos e mortes provocadas por esse crime apresentam índices ainda maiores. A ocultação, pela indústria do asbesto (amianto), dos perigos representados por seus produtos provavelmente custou tantas vidas quanto as destruídas

Fonte: BRASIL. Ministério da Justiça. Departamento Penitenciário Nacional - Sistema Integrado de Informações Penitenciárias (Infopen). Brasília, 2014. Disponível em: <http://www.justica.gov.br/seus-direitos/politica-

penal/documentos/infopen dez14.pdf>. Acesso em: 31 jul. 2017. 
por todos os assassinatos ocorridos nos Estados Unidos durante uma década inteira.

Uma realidade que inevitavelmente leva à conclusão de Flauzina (2006, p. 23):

\begin{abstract}
Os delitos cometidos pelos indivíduos dos grupos hegemônicos tem uma tendência a serem imunizados, em oposição aos praticados pelos segmentos vulneráveis, que são facilmente atingidos pelo sistema penal. Em decorrência disso, as estatísticas criminais ensejam interpretações distorcidas, indicando que a criminalidade é predominante entre os segmentos marginalizados, em razões de fatores sociais, tais como a pobreza, por exemplo.
\end{abstract}

Essa seletividade, que tira o foco de crimes tão nefastos como os de colarinho branco e que lota presídios por infrações de pequeno potencial ofensivo, não é exclusiva de determinada época ou sociedade. Rusche e Kirchheimer (2004) fizeram um levantamento analítico-histórico - estudo que influenciou a obra Vigiar e punir, de Michel Foucault, sobre os mecanismos punitivos de controle social - demonstrando que o controle penal sempre foi mais severo com as camadas economicamente inferiores. Durante e Idade Média, o direito criminal serviu como eficiente forma de manutenção hierárquica dos senhores feudais em relação aos servos. Por volta dos séculos XIV e XV, havia "diferentes aplicações da lei, feitas de acordo com a classe social do condenado" (Rusche; Kirchheimer, 2004, p. 31). Ainda segundo os autores, o surgimento do capitalismo trouxe uma preocupação redobrada com a propriedade, sendo a criação de leis para protegê-la "uma das principais preocupações da burguesia urbana emergente" (Rusche; Kirchheimer, 2004, p. 33). Essa preocupação de fato foi tomando corpo legal à medida que a burguesia ganhava influência no legislativo e judiciário - poderes que começavam a consolidar-se após as grandes revoluções.

A partir do século XVIII, segundo De Giorgi (2006), o controle social que antes era feito por meio da eliminação, pura e simplesmente, passa a operar por meio do controle legal. Aparentemente é uma evolução, já que as mudanças teriam uma função positiva, visando à recuperação. Mas o que ocorre é que "os pobres, vagabundos, prostitutas, alcoólatras e criminosos de toda espécie não são mais dilacerados, colocados na roda, aniquilados [...]. De forma muito mais discreta, silenciosa e eficaz, eles são encerrados" (De Giorgi, 2006, p. 26-27). 
A denúncia de Os miseráveis incide justamente sobre esse desequilíbrio do sistema punitivo, em que crimes de menor potencial ofensivo, comuns a determinada classe social, são punidos com severidade desproporcional aos danos provocados. Tendo isso em mente, Victor Hugo centra sua história no personagem Jean Valjean, condenado às desumanas galés pelo simples roubo de um pão:

É esta a segunda vez em que, nos seus estudos sobre a questão penal e a condenação pela lei, ao autor deste livro se depara o furto de um pão como ponto de partida para o desastre de toda uma existência. Claude Gueux havia roubado um pão, como Jean Valjean. Uma estatística inglesa constata que, em Londres, de cinco roubos, quatro têm como causa imediata a fome" (Hugo, 2012, p. 148).

Casos semelhantes ocorrem no Brasil com uma frequência espantosa.

Em 2015, uma mulher foi condenada no estado de São Paulo a 3 anos, 2 meses e três dias por ter roubado ovos de páscoa e um quilo de peito de frango, cumprindo a pena em uma cela superlotada (Cople, 2017; Bérgamo, 2017). A pena foi maior do que a imposta a vários réus da Operação LavaJato - investigação sobre desvios bilionários de verbas públicas. Já em Minas Gerais, um homem recebeu a condenação de 7 anos por roubar três cuecas e um par de meias usadas (Santos, 2011). Mas o caso mais inverossímil, semelhante ao de Jean Valjean, talvez seja o do pernambucano Marcos Mariano da Silva. Passou 19 anos preso por ser homônimo do verdadeiro acusado. Na prisão, contraiu tuberculose e ficou cego. Morreu poucas horas depois da notícia de que seria indenizado pelo erro (Miranda; Tinoco, 2016). O Superior Tribunal de Justiça (STJ) definiu esse como "o maior e mais grave atentado à violação humana já visto na sociedade brasileira” (Rêgo, 2011, n.p.).

Esses casos têm em comum a situação de hipossuficiência dos acusados, que foram prejudicados pela deficiência no acesso à justiça. $\mathrm{O}$ aparato judicial não consegue garantir um procedimento igualitário aos que não tem condições financeiras de custear uma assessoria jurídica. Não existem dados oficiais sobre condenações injustas devido à situação socioeconômica, parecendo não haver interesse estatal no assunto:

O Departamento Penitenciário Nacional (Depen) diz não contar com estudos a respeito de condenados injustamente e sugere uma consulta aos bancos de dados do Conselho Nacional de Justiça (CNJ); já o CNJ afirma 
não acompanhar esses casos e sugere que o Depen seja procurado (Miranda; Tinoco, 2016).

Embora não existam dados de abrangência nacional, há alguns estudos regionais. Esse é o caso do programa de extensão da faculdade ASCES/UNITA, no município de Caruaru-PE, que em 10 anos, apenas naquele município, "liberou mais de 200 cidadãos indevidamente presos" (Alves Ribeiro et al., 2015), graças à assistência jurídica gratuita. A grande maioria foi vítima da própria condição de pobreza, que não permitiu uma defesa de nível básico. Méndez (2000, p. 247) confirma que "o problema real é que as mulheres, as crianças, os povos indígenas, os camponeses semterra, os presidiários, os doentes internados e outros setores igualmente carentes de nossas sociedades simplesmente não têm acesso à justiça”.

Nos crimes comuns aos economicamente favorecidos, entretanto, ocorre o inverso, já que esses têm acesso aos melhores profissionais no ramo do direito, garantindo não apenas uma defesa mais justa, mas em muitos casos a própria impunidade - e não apenas no Brasil. Coleman (2005, p. 287) assim descreve a situação:

A chance que os réus de colarinho branco têm de pagar uma defesa de primeira linha - os melhores advogados, numerosas apelações e, caso necessário, investigadores particulares e testemunhas - provavelmente é muito mais relevante. Muitos ex-réus admitem abertamente que a possibilidade de "contratar o melhor" foi um fator decisivo para sua causa. Conklin cita o exemplo de um milionário do ramo petrolífero no Texas que admitiu ter sido absolvido de acusações de escuta clandestina de telefones pois gastara mais de 1 milhão de dólares em sua própria defesa.

Não basta que as cartas constitucionais garantam em seus textos o acesso à justiça, porque

Os tribunais e os serviços legais são em teoria disponíveis para todos, do mesmo modo que no Sheraton Hotel qualquer um pode entrar; tudo que se precisa ter é dinheiro. A verdade é que a justiça é uma mercadoria cara, mesmo naqueles países com os mais altos níveis de educação e uma generosa alocação de despesas com bemestar social (GARRO, 2000, p. 308)

Estudos internacionais já verificaram que o judiciário brasileiro é um dos mais desiguais do mundo. Moura (2017) divulgou estudo da ONG World Justice Project em que o país figura na $94^{\mathrm{a}}$ posição, entre 101 países, quando o requisito é discriminação no sistema criminal. 
Essa é a denúncia que Victor Hugo faz ao retratar seu personagem preso por 19 anos porque não tinha como se defender, já que "em sua meninice, não havia aprendido a ler. Adulto, tornou-se podador de árvores” (Hugo, 2012, p. 143), caso corriqueiro no Brasil e na América Latina como um todo, onde, segundo Garro (200, p. 308) afirma, os pobres não têm "acesso ao serviço legal, tribunais e instituições formais legais. Por ignorância, falta de poder de barganha [...] ou mesmo medo de que a máquina judiciária funcionará contra eles”. Da mesma forma Brodeur (2000, p. 101) destaca:

Em toda sociedade que tenho estudado, a resposta a questões como "quem vem sendo punido nesta sociedade" ou "quem está na prisão" geralmente é: aqueles segmentos da população que são menos poderosos e não-privilegiados. (...) o direito penal tem por alvo, principalmente, em sua definição e aplicação, o crime de rua, que é perpetrado pelo pobre e membros excluídos da sociedade.

Assim, na narrativa do romance, Valjean é a encarnação de toda essa massa de injustiçados, excluídos de uma apreciação justa de suas causas, e o inspetor Javert simboliza a irônica figura do judiciário, com seus ideais iluministas, mas com o braço pesado sobre um dos lados da balança. Os inúmeros confrontos entre os dois personagens não é simples maniqueísmo, mas uma representação do único resultado possível de um sistema judiciário desigual: a promoção da injustiça. A mesma conclusão que chegou Cook (2000, p. 127): “A discriminação de marginalizados não é simplesmente uma falta de sorte associada a seus status particulares, mas uma injustiça”.

A questão aprofunda-se ainda mais no romance. A partir de Jean Valjean, constata-se não apenas a realidade de um aparato judicial ineficiente e promotor de injustiças, mas também um instrumento que pune duplamente. As reflexões de Valjean são as mesmas de Marcos Mariano, da mãe que roubou os ovos de páscoa e tantos outros:

Nessa história toda, o erro era só dele? Era igualmente grave o fato de ele, trabalhador, não ter trabalho; ele, trabalhador, não ter pão. Depois de a falta ter sido cometida e confessada, o castigo não foi por demais feroz e excessivo? Onde haveria mais abuso: da parte da lei, na pena, ou da parte do culpado, no crime? Não haveria excesso de peso em um dos pratos da balança, justamente naquele em que está a expiação? Será que o exagero da pena não apagava completamente o crime, quase que 
invertendo a situação, fazendo do culpado vítima, do devedor credor, pondo definitivamente o direito justamente do lado de quem cometeu o furto? Essa pena, aumentada e agravada pelas sucessivas tentativas de fuga, não era, por acaso, uma espécie de atentado do mais forte contra o mais fraco, um crime da sociedade contra o indivíduo, um crime que todos os dias se renovava, um crime que se estendeu por dezenove anos?” (Hugo, 2012, p. 150).

Bolívar (2000, p. 57) afirma que as pessoas pobres não estão apenas à margem nos campos econômico, político e social, mas "elas são duplamente vítimas: primeiro pelos executores dos abusos e depois pelo sistema que reluta em agir no interesse delas”. É a lógica desse tipo de punição, como visto em seu desenvolvimento histórico. Foi o que Rusche e Kirchheimer (2004, p. 20) constataram: "para combater o crime entre os extratos sociais desprivilegiados, as penalidades precisam ser de tal forma que estes temam uma piora em seus modos de existência”. Essa piora equivale a outra condenação.

O cerne dessa punição não é a privação da liberdade em si, mas o local a que estão destinados os condenados: a prisão. Embora os inúmeros códigos baseiem sua criação e manutenção sob o argumento de promover a ressocialização, não é segredo para sociedade alguma que em geral trata-se apenas de depósitos humanos, como nos resume a precisa análise de Sequeira (2006, p. 668):

A prisão é uma lixeira humana, um lugar de horror, de total invisibilidade, um lugar de aniquilamento do homem, de aprisionamento do ser. Condições desumanas, ou, como me ensinam os presos, um lugar onde não se dorme sossegado, onde ninguém confia em ninguém, nem se garante quem estará vivo amanhã, um lugar fora da lei. Em nome da lei e de um suposto tratamento penal, encontramos homens abandonados, em bandos, excluídos, sem lugar, embora incluídos pela lei. Uma constatação é inevitável: o não-lugar mata o homem em vida. É um absurdo que, em nome da lei, alguém tenha que se submeter a condições subumanas de vida, não tenha possibilidades de desenvolvimento pessoal, cultural, educacional ou de formação e qualificação profissional, que tenha que se submeter a regras de sociabilidade nas quais predomina uma lógica de favores e benefícios ditados por aqueles que têm poder sobre os outros, inclusive sobre a vida dos outros.

Quase 200 anos antes, Victor Hugo fazia uma descrição das prisões temporárias de Paris, descrição que mais parece um complemento ao estudo de Sequeira (2006) citado acima: 
Havia no Châtelet de Paris um longo subterrâneo, situado oito pés abaixo do nível do Sena. Não tinha nem janelas nem respiradouros; a única abertura era a porta; os homens podiam entrar, o ar não. [...] Aí eram jogados os homens condenados às galés até que fossem transportados para Toulon. [...] Prendiam-nos e ali os abandonavam. Como a corrente era por demais curta, eles não podiam deitar-se. Ficavam imóveis naquele subterrâneo, naquela noite [...]. Era a antecâmara das galés. Era-se jogado ali por causa de uma simples lebre roubada ao Rei. Naquele sepulcro-inferno, que faziam eles? O que se pode fazer num sepulcro: agonizavam; e o que se pode fazer num inferno: cantavam, pois, onde não restam mais esperanças, o canto continua. (Hugo, 2012, p. 1355)

Esse relato de homens quase sem respirar ou se mover mais parece, de fato, um diário das prisões brasileiras. A organização internacional não governamental Human Rights Watch, protetora dos direitos humanos, constatou em seu relatório de 2016 que a ocupação das prisões já atinge um contingente que ultrapassa $60 \%$ a capacidade de encarceramento. Não apenas a seletividade no rigor da aplicação da lei, mas também o ambiente de cumprimento da pena é diferente quando se trata de classe social. Essa realidade carcerária tão bem descrita por Victor Hugo (2012) é quase que exclusiva, mais uma vez, dos desfavorecidos economicamente. A despeito da motivação aparente do legislador, há previsão legal no ordenamento jurídico brasileiro de um tipo de prisão diferenciado para determinadas pessoas. Portador de diploma de nível superior é um desses casos, o que é uma forma institucionalizada de diferenciação social, já que, no Brasil, quanto maior o tempo de estudo, maior a renda (De Vizia, 2008). Cury Jamil e Nogueira (2001, p. 105) afirmam que esses mecanismos "constituem uma forma a mais de legitimação de diferenças sociais, tendo como pano de fundo a manutenção de hierarquias na sociedade brasileira e seu cruzamento com as desigualdades sociais e as discriminações existentes".

E os números falam por si. No estudo de Monteiro e Cardoso (2013, p. 105), foi constatado que entre os presos " $77 \%$ não haviam passado do ensino fundamental" e que "a maioria das pessoas encarceradas é de baixíssima escolaridade".

Não bastasse dispositivo legal excludente, a prática na interpretação, no entanto, pode ser ainda mais cruel para quem não tem como arcar com o custo de uma boa defesa técnica no judiciário. Caso emblemático foi o do 
empresário brasileiro Eike Batista, que teve a prisão preventiva decretada no dia 13 de janeiro de 2017, devido ao seu suposto envolvimento em um esquema de corrupção (Martín, 2017). Foi encaminhado para o presídio superlotado Ary Franco, conhecido como "masmorra", no estado do Rio de Janeiro. Embora não tenha diploma de curso superior, passou menos de duas horas no local, transferido para penitenciária com melhores condições. A alegação foi de que havia risco para sua segurança no local (Vettorazzo, 2017). Os cerca de 2.000 presos do Ary Franco continuaram suas vidas sem segurança no mesmo lugar.

A carceragem da polícia federal em Curitiba talvez seja o símbolo máximo - e a confirmação - de que há dois tipos de prisioneiros no país. Para lá são encaminhados alguns réus da operação Lava-jato, que em sua maioria são empresários e detentores de altos cargos nos poderes Executivo e Legislativo. A lotação máxima das celas é de 3 pessoas, cerca de $6 \mathrm{~m}^{2}$ por pessoa, em um momento de lotação máxima (Oliveira, 2015). Não é incomum encontrar cadeias e presídios com menos de $1 \mathrm{~m}^{2}$ por preso (Yafusso, 2016). A Lei de Execuções Penais falha já no início, pois prevê em consonância com o texto constitucional - que "não haverá discriminação alguma baseada em raça, cor, sexo, língua, religião, opinião política ou qualquer opinião, origem nacional ou social, fortuna, nascimento ou em qualquer outra situação" (Batistela; Amaral, 2009, p. 2).

Como coparticipante dessas exceções institucionalizadas está a sociedade, que passivamente aceita essa diferenciação. Não apenas aceita, mas contribui para tal. No imaginário popular, o crime está associado à imagem do bandido marginal, habitante dos guetos e favelas, e muito pouco ao engravatado de classe alta, sendo mais fácil moer quem já não tem nada. Victor Hugo (2012, p. 47) questiona a hostilidade fácil ao marginal, afirmando que a sociedade será "culpada de não instruir gratuitamente e responderá pela escuridão que provoca. Uma alma na sombra da ignorância comete um pecado? A culpa não é de quem o faz, mas de quem provocou a sombra".

Uma sociedade que sabe o que se passa nas prisões país afora, mas que, ao calar, concorda que essa situação é parte da punição - merecida, por sinal. Chevigny (2000, p. 71), ao analisar a violência policial verificada junto aos pobres, constata que 
Quando a polícia militar matou 111 prisioneiros [...] na casa de detenção de São Paulo, em resposta a uma rebelião em 1992, uma grande porcentagem da população disse que aprovava a polícia, e quando uma equipe de TV filmou a própria execução de um suspeito no pátio de um shopping do Rio em 1995, a maioria dos pesquisados apoiou o crime. A opinião geral é que a privação de liberdade pessoal não é a única punição associada com detenção: não se espera que as prisões sejam confortáveis e as pessoas resignem-se a serem sujeitas a uma variedade de sofrimentos adicionais, sendo a coerção física uma delas.

Em Os miseráveis, como já analisado, essa sociedade, "tão formidável para quem está do lado de fora, tão terrível para os que são por ela sobrepujados" (HUGO, 2012, p. 156), é personificada no inspetor Javert e sua incansável luta pela justiça. Ao tentar recapturar o foragido Jean Valjean, pensa contribuir para um mundo mais justo, no qual o estado é garantidor da ordem social. Entretanto, em um confronto nas barricadas da revolução em Paris, Valjean tem a oportunidade de pôr fim à vida do seu algoz, mas o liberta.

A crise de consciência experimentada por Javert após o evento é o ponto de reflexão que o autor pretende impor à sociedade, desconstruindo todo o ideal constitucionalista de que o mundo estaria seguro sob o governo das leis:

\begin{abstract}
A sociedade, o gênero humano e o universo se resumiam agora, a seus olhos, num esboço simples e terrível - a penalidade, a coisa julgada, a força devida à legislação, as sentenças das cortes soberanas, a magistratura, o governo, a prevenção e a repressão, a sabedoria oficial, a infalibilidade da lei, o princípio da autoridade, todos os dogmas sobre os quais repousa a segurança política e civil, a soberania, a justiça, a lógica derivada do código, o absoluto social, a verdade pública, tudo isso não passava de escombros, entulho, caos" (Hugo, 2012, p. 1789).
\end{abstract}

A ficção jurídica do contrato social é então posta à prova, expondo um aparato judicial que funciona mais como instrumento de perpetuação de privilégios do que garantidor dos vulneráveis frente à tirania. Espíndola (2017, p. 313) traduz essa realidade ao dizer que o direito pode ser conduzido "à arbitrariedade, na medida em que [...] nada mais terá a falar, visto que, na sua generalidade e realização concreta, é condicionalmente determinado pelos interesses política ou socialmente mais adequados".

A reflexão de Javert atravessa décadas e continua desafiando uma sociedade acomodada do outro lado do Atlântico. Dias e Dias (2011, p. 55) 
traduzem a angústia do inspetor ao afirmar que "não cabe apenas ao direito garantir a disciplina e controle da sociedade, é indispensável que assegure a prevalência dos valores humanos sobre todas as formas de dominação, exploração e exclusão social”.

\section{CONSIDERAÇÕES FINAIS}

Victor Hugo subverte o imaginário popular - tanto na França do século XIX como no Brasil contemporâneo - do condenado penal como indivíduo perigoso e selvagem, que deve ser acorrentado e mantido o mais longe possível da sociedade, visto com desconfiança pelo resto da vida. Ao escolher um presidiário como personagem principal de seu épico romance, ao lhe fornecer uma história e uma conduta heroica, o autor concede voz a essa parcela estereotipada, que carrega um estigma por vezes imerecido e em boa parte desproporcional ao delito cometido. Entende-se a dimensão dessa obra quando se consideram os efeitos danosos de uma visão segmentária, que retira qualquer humanidade desses indivíduos. Crochik (1972, p. 22 apud Sequeira, 2006) sintetiza de forma clara como um imaginário preconcebido pode ter consequências sérias e duradouras:

O estereótipo do criminoso como um indivíduo de alta periculosidade, intratável, mau-caráter, auxilia na caracterização que o indivíduo saudável deve ter para saber como agir quando se defrontar com o mesmo, ao mesmo tempo em que impede a identificação com ele. Quanto mais distintos julgarmos que somos dele, mais protegidos nos sentiremos dos impulsos hostis que nos pertencem. Nesse sentido, os estereótipos evitam termos de pensar como as condições sociais nas quais vivemos e que fortalecemos contribuem para o crime, e quanto nós próprios, nessas condições, poderíamos cometê-los. Em outras palavras, evitam a reflexão sobre o mundo social e sobre nós mesmos.

Ver o criminoso e todo o sistema penal através de Os miseráveis é experimentar o lugar do condenado e perceber que não há essa distinção. É um experimento em empatia que revela como as bandeiras levantadas desde as grandes revoluções do século XVIII, em especial a francesa, continuam na pauta das nações, e do Brasil em particular. O ideal de igualdade continua como a maioria dos ideais - distante da realidade. $\mathrm{O}$ mais perigoso é a falsa ideia de segurança jurídica, pois o fato de o judiciário brasileiro ter se consolidado como instituição independente ou mesmo que o legislativo tenha liberdade para legislar não é garantia de 
justiça. A desigualdade social permanece como uma das piores violações no estado de direito.

Um dos pontos que se extrai da leitura do romance, e que talvez seja a principal contribuição dessa análise interdisciplinar, é a própria legitimidade da lei. A presunção da norma correta, principalmente por parte dos operadores do direito, perpetua esse tipo de injustiça, que é a mais letal, pois já passou pelo crivo do judiciário:

\begin{abstract}
Haverá maior insegurança do que uma determinação sem limites, através da legislação, do que é permitido ou proibido, além do mais realizada por um certo poder que se dispensa de provar a própria legitimidade? Este poder, ao contrário, se presume legítimo, a partir do fato de que está em exercício e chegou à posição desempenhada, seguindo os processos que ele próprio estabelece, altera e, de todas as formas, controla a seu bel-prazer (Lyra Filho, 2012, p. 37-38).
\end{abstract}

É papel da academia permanecer como um centro de reflexão e resistência a todo tipo de tirania. E esta parece levantar-se ininterruptamente na história humana, embora mudem as vestes, suas garras estão sempre à mostra, por meio das armas ou através das leis, como o faz atualmente. Inserir a literatura no debate é revestir de humanidade o dogmatismo, é dar voz e história aos milhões de encarcerados, como humanos que são. Esses miseráveis são ainda ouvidos e notados graças à ótica visionária de Victor Hugo e sua fascinante epopeia parisiense. Seus personagens podem ser encontrados pelas ruas e prisões de todo o Brasil atual, sofrendo dupla punição, que na opinião de muitos brasileiros ainda é branda.

Não é apenas uma faculdade, mas um dever dos estudiosos e operadores do direito criticar o sistema legal vigente e sua aplicação. A literatura nos dá o alerta e, através do personagem Javert, evidencia que é preciso reconhecer a tirania da lei e adotar uma conduta mais ativa no combate às desigualdades. Afinal, enquanto houver miséria, haverá injustiça.

\title{
REFERÊNCIAS
}

ADORNO, Sérgio. Crise no sistema de justiça criminal. Ciência e cultura, v. 54, n. 1, p. 50-51, 2002.

ALVES RIBEIRO, Maria Edna et al. Programa de extensão "Adoção Jurídica de Cidadãos Presos": quatorze anos de cidadania, humanização e acesso à justiça. Extramuros, Petrolina-PE, v. 3, n. 3, p. 62- 81, 2015. Disponível

em: 
<http://www.periodicos.univasf.edu.br/index.php/extramuros/article/vie wFile/771/489 >. Acesso em: 18 set. 2017.

BARROS FILHO, Armando Dantas de. Educação física e direitos humanos em prisões: uma análise das ações de educação física e esporte na educação de jovens e adultos em privação de liberdade. 2014. $160 \mathrm{f}$. Dissertação (Mestrado em Direitos Humanos) - Universidade Federal da Paraíba, João Pessoa, 2014.

BATISTELA, Jamila Eliza; AMARAL, Marilda Ruiz Andrade. As regras mínimas para o tratamento de prisioneiros da ONU e a Lei de Execução Penal brasileira: uma breve comparação. ETIC- Encontro de Iniciação Científica, v. 4, n. 1, 12, 2009. Disponível em: <http://intertemas.toledoprudente.edu.br/revista/index.php/ETIC/article /view/1661/1583> Acesso em: 18 set. 2017.

BERGAMO, Monica. Mãe é condenada a pena maior que de réus da Lava Jato por roubar ovos de Páscoa. Folha de São Paulo, 22/05/2017. Disponível em: <http://www1.folha.uol.com.br/colunas/monicabergamo/2017/05/188573 1-mae-e-condenada-a-pena-maior-que-de-reus-da-lava-jato-por-roubarovos-de-pascoa.shtml?cmpid=twfolha $>$. Acesso em: 18 set. 2017.

BOLIVAR, Ligia. Comentários sobre Rodley. In: MÉNDEZ, Juan E.; O'DONNEL, Guillermo; PINHEIRO, Paulo Sérgio. Democracia, violência e injustiça: o não estado de direito na América Latina. São Paulo: Paz e Terra, 2000. p. 57-63.

BRAGA, Paulo Drumond. Os forçados das galés: percursos de um grupo marginalizado. In: BARROCA, Mario Jorge (Coord.). Carlos Alberto Ferreira de Almeida: in memoriam, v. 1, Porto; Faculdade de Letras da Universidade do Porto, 1999. p. 187-200. Disponível em: $<$ https://archive.org/details/CarlosAlbertoFerreiraDeAlmeidaInMemoriam $>$. Acesso em: 18 set. 2017.

BRODEUR, Jean-Paul. Comentário sobre Chevigny. In: MÉNDEZ, Juan E.; O’DONNEL, Guillermo; PINHEIRO, Paulo Sérgio. Democracia, violência e injustiça: o não estado de direito na América Latina. São Paulo: Paz e Terra, 2000. p. 89-104.

BROCA, Brito. Em torno do pioneirismo do romance "Os miseráveis". Estadão, 14/05/2010. Disponível em: <http://cultura.estadao.com.br/noticias/geral,em-torno-do-pioneirismodo-romance-os-miseraveis,551976>. Acesso em: 18 set. 2017.

CERQUEIRA, Daniel; LOBÃO, Waldir; CARVALHO, Alexandre X. de. $O$ jogo dos sete mitos e a miséria da segurança pública no Brasil. Rio de Janeiro: 2005. Disponível em: < http://repositorio.ipea.gov.br/bitstream/11058/1778/1/TD 1144.pdf $>$. Acesso em: 18 set. 2017.

COLEMAN, James William. A elite do crime: para entender o crime do colarinho branco. Barueri: Manole, 2005.

COOK, Rebecca J. Superando a discriminação: introdução. In: MÉNDEZ, Juan E.; O'DONNEL, Guillermo; PINHEIRO, Paulo Sérgio. Democracia, violência e injustiça: o não estado de direito na América Latina. São Paulo: Paz e Terra, 2000. p. 127-134. 
COPLE, Julia. Mãe é condenada a pena maior que réus da Lava-Jato por roubar ovos de páscoa. Extra, 22/05/2017. Disponível em: $<$ https://extra.globo.com/noticias/brasil/mae-condenada-pena-maiorque-reus-da-lava-jato-por-roubar-ovos-de-pascoa-21374988.html $>$. Acesso em: 18 set. 2017 .

CROCHIK, José L. Preconceito, indivíduo e cultura. 2. ed. São Paulo: Robe, 1997.

CURY JAMIL, Carlos Roberto; NOGUEIRA, Maria Alice. Prisão especial e diploma de ensino superior: uma aproximação crítica. Revista Brasileira de Educação, n. 16, p. 105-115, 2001. Disponível em: $<$ http://www.scielo.br/scielo.php?script=sci arttext\&pid=S141324782001000100011\&lng=en\&nrm=iso >. Acesso em: 18 set. 2017. doi: http://dx.doi.org/10.1590/S1413-24782001000100011.

DE GIORGI, Alessandro. A miséria governada através do sistema penal. Rio de Janeiro: Revan; Instituto Carioca de Criminologia, 2006.

DE VIZIA, Bruno. Para cada ano de estudo, renda aumenta $15 \%$, mostra a FGV. Gazeta Mercantil Online, 10/10/2008. Disponível em: <http://www.cps.fgv.br/ibrecps/iv/midia/kc1654.pdf $>$. Acesso em: 18 set. 2017.

DIAS, Maria da Graça dos Santos; DIAS, Túlio César. Referentes para uma (re) construção humanística do direito Novos Estudos Jurídicos, p. 4559, ago. 2011. Disponível em: <https://siaiap32.univali.br/seer/index.php/nej/article/view/3119>.

Acesso em: 18 set. 2017. doi: http://dx.doi.org/10.14210/nej.vono.p45-59.

DMITRUK, Erika Juliana. O princípio da integridade como modelo de interpretação construtiva do Direito em Ronald Dworkin. Revista jurídica da Unifil, Londrina, ano IV, n. 4, p. 144-155, 2007. Disponível em: $<$ http://www.unifil.br/portal/images/pdf/documentos/revistas/revistajuridica/edicao-2007.pdf $>$. Acesso em: 18 set. 2017.

DIMOULIS, Dimitri. Manual de introdução ao estudo do direito. São Paulo: Editora Revista dos Tribunais, 2011.

ESPÍNDOLA, Angela Araújo da Silveira. Entre a insustentabilidade e a futilidade: a jurisdição, o direito e o imaginário social sobre o juiz. Anamorphosis - Revista Internacional de Direito e Literatura, Porto Alegre, v. 2, n. 2, p. 293-320, jan. 2017. Disponível em: <http://rdl.org.br/seer/index.php/anamps/article/view/254>. Acesso em: 8 abr. 2018. doi: http://dx.doi.org/10.21119/anamps.22.293-320.

FERNANDES, Newton; FERNANDES, Valter. Criminologia integrada. São Paulo: Editora Revista dos Tribunais, 2012.

FERREIRA, Iverson Kech. Os miseráveis e os estudos criminais de Victor Hugo. Disponível em: <https://canalcienciascriminais.com.br/osmiseraveis-e-os-estudos-criminais-de-victor-hugo/>. Acesso em: 18 set. 2017. 
FAJNZYLBER, Pablo; ARAUJO JR, Ari. Violência e criminalidade; Texto para Discussão n. 167. Belo Horizonte: UFMG, 2001. Disponível em: $<$ https://www.researchgate.net/profile/Pablo Fajnzylber/publication/480 5609 Violencia e criminalidade Violence and criminality/links/02e7e 5 33 ee3512f970000000/Violencia-e-criminalidade-Violence-andcriminality.pdf $>$. Acesso em: 8 abr. 2018.

FLAUZINA, Ana Luiza Pinheiro. Corpo negro caído no chão: o sistema penal e o projeto genocida do Estado brasileiro. 2006. 145 f. Dissertação (Mestrado em Direito)-Universidade de Brasília, Brasília, 2006. Disponível em: <http://repositorio.unb.br/handle/10482/5117>. Acesso em: 18 set. 2017.

GARRIDO, Adriana Cristina Oliver. Fatores sociais de criminalidade. Revista sistema penal \& violência, v. 4, [s./p.], 2016.

GARRO, Alejandro M. Acesso à justiça para os pobres na América Latina. In: MÉNDEZ, Juan E.; O’DONNEL, Guillermo; PINHEIRO, Paulo Sérgio. Democracia, violência e injustiça: o não estado de direito na América Latina. São Paulo: Paz e Terra, 2000. p. 307-335.

GODOY, Arnaldo Moraes. Direito e literatura. Revista CEJ, Brasília, v. 7, n. 22, p. 133-136, 2003. Disponível em: <http://www.cjf.jus.br/ojs2/index.php/revcej/article/view/573/753>. Acesso em: 18 set. 2017.

HAGAN, J.; PETERSEN, R. D. Crime and inequality. Stanford University Press, 1995 .

HUGO, Victor. Os trabalhadores do mar. São Paulo: Abril Cultural, 1979.

HUGO, Victor. Os miseráveis. São Paulo: Cosac Naify, 2012.

HUMAN Rights Watch. Relatório Mundial 2016: Brasil. Disponível em: <https://www.hrw.org/pt/world-report/2016/country-chapters/285573>. Acesso em 18 set. 2017.

HUNT, Lynn. A invenção dos direitos humanos. São Paulo: Companhia das Letras, 2007.

LLANOS, Leonor Suárez. Literatura do direito: entre a ciência jurídica e a crítica literária. Anamorphosis - Revista Internacional de Direito e Literatura, Porto Alegre, v. 3, n. 2, p. 349-386, jan. 2018. Disponível em: $<$ http://rdl.org.br/seer/index.php/anamps/article/view/320 $>$. Acesso em: 8 abr. 2018. doi: http://dx.doi.org/10.21119/anamps.32.349-386.

LLOSA, Mario Vargas. A tentação do impossível: Victor Hugo e "Os miseráveis”. Rio de Janeiro: Objetiva, 2012.

LYRA FILHO, Roberto. O que é direito. São Paulo. Editora Brasiliense, 2012

MARTÍN, María. Eike Batista é preso pela PF no Rio após 3 dias foragido. El País, 30/01/2017. Disponível em: $<$ https://brasil.elpais.com/brasil/2017/01/30/politica/1485776114 14036 o.html $>$. Acesso em: 18 set. 2017. 
MÉNDEZ, Juan E. Reforma institucional, inclusive acesso à justiça: introdução. In: MÉNDEZ, Juan E.; O’DONNEL, Guillermo; PINHEIRO, Paulo Sérgio. Democracia, violência e injustiça: o não estado de direito na América Latina. São Paulo: Paz e Terra, 2000. p. 243-248.

MENDONÇA, Mário Jorge Cardoso de; SACHSIDA, Adolfo; LOUREIRO, Paulo Roberto Amorim. Criminalidade e desigualdade social no Brasil. Brasília: IPEA, 2003. Disponível em: $<$ http://ipea.gov.br/agencia/images/stories/PDFs/TDs/td 0967.pdf $>$.

Acesso em: 18 set. 2017.

MIRANDA, André; TINOCO, Dandara. As injustiças da justiça brasileira. $O$ Globo, 26/o1/2016. Disponível em: <https://oglobo.globo.com/brasil/asinjusticas-da-justica-brasileira-18541969>. Acesso em: 11 nov. 2017.

MONTEIRO, Felipe Mattos; CARDOSO, Gabriela Ribeiro. A seletividade do sistema prisional brasileiro e o perfil da população carcerária: um debate oportuno. Civitas - Revista de Ciências Sociais, [S.l.], v. 13, n. 1, p. 93-117, ago. 2013. ISSN 1984-7289. Disponível em: $<$ http://revistaseletronicas.pucrs.br/ojs/index.php/civitas/article/view/12 592>. Acesso em: 18 set. 2017. doi: http://dx.doi.org/10.15448/19847289.2013.1.12592.

MOREIRA, Elana Gomes Santos. Direito e literatura: a importância da literatura no direito. Diké: Revista Eletrônica de Direito, Filosofia e Política do Curso de Direito da UNIPAC Itabirito, ano 6, n 9, $1^{\circ}$ semestre de 2014. Disponível

em: $<$ http://faculdadealis.com.br/uploads/faculdade alis 2017/arquivos/revis ta1de2014-635797483707998605.pdf $>$. Acesso em: 4 abr. 2018.

MOURA, Carlos. A desigual Justiça brasileira: uma análise de dados e estratégias de mudança. Justificando: mentes inquietas pensam direito. Carta Capital, 15/05/17. Disponível em: $<$ http://justificando.cartacapital.com.br/2017/05/15/desigual-justicabrasileira-uma-analise-de-dados-e-estrategias-de-mudanca/>. Acesso em: 30 set. 2017.

OLIVEIRA, Germano. Carceragem da PF em Curitiba atinge lotação máxima com novos presos. O Globo online, 20/06/16. Disponível em: $<$ https://oglobo.globo.com/brasil/carceragem-da-pf-em-curitiba-atingelotacao-maxima-com-novos-presos-16505930>. Acesso em: 31 jul. 2017.

OLIVO, Luis Carlos Cancellier de. $O$ estudo do direito através da literatura. Tubarão Studium, 2005. Disponível em: $<$ https://repositorio.ufsc.br/xmlui/handle/123456789/99642>. Acesso em: 18 set. 2017.

PELLEGRINI, Marcelo. Discriminação socioeconômica e de raça está por todo sistema criminal, afirma estudo. Sociedade: USP, 03/12/11. Disponível em: $\quad<$ http://www5.usp.br/3953/discriminacao-esta-por-todo-sistemacriminal-afirma-estudo/>. Acesso em: 30 jul. 2017.

RÊGO, Roberta. No Recife, ex-mecânico morre depois de saber que ganharia indenização. Nov. 2011. Disponível em: http://g1.globo.com/pernambuco/noticia/2011/11/no-recife-ex-mecanicomorre-depois-de-saber-que-ganharia-indenizacao.html. Acesso em 20 maio 2018. 
RESENDE, João Paulo de; ANDRADE, Mônica Viegas. Crime social, castigo social: desigualdade de renda e taxas de criminalidade nos grandes municípios brasileiros. Estudos Econômicos, São Paulo, v. 41, n. 1, p. 173195, mar. 2011.2 Disponível em: <https://www.revistas.usp.br/ee/article/view/36039>. Acesso em: 18 set. 2017. doi: http://dx.doi.org/10.1590/So101-41612011000100007.

RIBEIRO, Renato Janine. Prefácio. In: HUGO, Victor. Os miseráveis. São Paulo: Cosac Naify, 2012. p. 17-26.

ROCHA, Sonia. Pobreza e desigualdade no Brasil: o esgotamento dos efeitos distributivos do Plano Real. Rio de Janeiro: IPEA, 2000. Disponível em: $<$ http://repositorio.ipea.gov.br/bitstream/11058/2365/1/TD 721.pdf $>$.

Acesso em: 18 set. 2017.

RUSCHE, Georg; KIRCHHEIMER, Otto. Punição e estrutura social. Rio de Janeiro: Instituto Carioca de Criminologia, 2004.

SANTOS, Débora. Justiça absolve condenado a sete anos por roubo de cuecas usadas. Portal de notícias G1, 17/06/2011. Disponível em: <http://g1.globo.com/politica/noticia/2011/06/justica-absolvecondenado-sete-anos-por-roubo-de-cuecas-usadas.html $>$. Acesso em: 18 set. 2017.

SANTOS, Carlos Cesar Carneiro. Direito na obra "Os miseráveis" de Víctor Hugo: um diálogo sob a ótica da escola de direito crítico. Âmbito Jurídico. Disponível em: <http://ambitojuridico.com.br/site/?n link=revista artigos leitura\&artigo $\mathrm{id}=16803>$. Acesso em: 27 jun. 2017.

SCHWARTZ, Germano; MACEDO, Elaine. Pode o Direito ser Arte? Respostas a Partir do Direito \& Literatura. In: XV CONGRESSO NACIONAL DO CONPEDI, Manaus, 2006. Disponível em: <http://www.publicadireito.com.br/conpedi/manaus/arquivos/anais/salva dor/germano schwartz.pdf $>$. Acesso em: 18 set. 2017.

SHECAIRA, Sérgio Salomão. Criminologia. São Paulo: Editora Revista dos Tribunais, 2014.

SEQUEIRA, Vania Conselheiro. Uma vida que não vale nada: prisão e abandono político-social. Psicol. cienc. prof., Brasília, v. 26, n. 4, p. 66o671 , dez. 2006.

Disponível

em:<http://www.scielo.br/scielo.php?script=sci_arttext\&pid=S1414-

98932006000400012\&lng=en\&nrm=iso $>$. Acesso em: 18 set. 2017. doi: 10.1590/S1414-98932006000400012.

YAFUSSO, Paulo. Com superlotação, preso ocupa menos de um metro quadrado. Campo Grande News, 07/05/16. Disponível em: $<$ https://www.campograndenews.com.br/cidades/capital/comsuperlotacao-preso-ocupa-menos-de-um-metro-quadrado $>$. Acesso em: 18 set. 2017.

VETTORAZZO, Lucas. De cabelo raspado, Eike Batista é transferido para o presídio de Bangu 9. Folha de São Paulo, 30/o1/2017. Disponível em: <http://www1.folha.uol.com.br/poder/2017/01/1854209-de-cabeloraspado-eike-batista-e-transferido-para-o-presidio-de-bangu-9.shtml >. Acesso em: 18 set. 2017. 
VIEIRA, Oscar Vilhena. Império da lei ou da corte?. Revista USP, Brasil, n. 21, p. 70-77, maio 1994. Disponível em: <http://www.revistas.usp.br/revusp/article/view/26937>. Acesso em: 18 set. 2017. doi: 10.11606/issn.2316-9036.v0i21p70-77.

Idioma original: Português

Recebido: 01/10/17

Aceito: 04/04/18 